DOI 10.37882/2500-3682.2021.11.11

\title{
ПРОБЛЕМА ВЫБОРА СПОСОБОВ ПООЩРЕНИЯ ЭТИЧНОГО ПОВЕДЕНИЯ В ПРОФЕССИОНАЛЬНОМ КОЛЛЕКТИВЕ
}

\section{THE PROBLEM OF CHOOSING WAYS TO ENCOURAGE ETHICAL BEHAVIOR IN A PROFESSIONAL TEAM}

V. Puhir

Summary: The article examines the factors that make people remain silent about bad behavior at work, as well as strategies that team leaders and ordinary employees can use to change the culture of communication in a professional team and strengthen civic position. Based on specific social observations, the author explains why people at work do not always defend their own values and ideals, and shows how this can be changed. The article presents the types, forms and methods of encouraging the ethical behavior of employees. Particular attention is paid to non-material forms of encouragement.

Keywords: communication, ethical behavior, motivation, encouragement, silence, protest, leader, culture of expression.
K аждый день мы слышим и читаем о нарушениях социальных норм: коррупции, абъюзе, эмоциональном и физическом насилии, сексизме, троллинге, буллинге и т.п. Это то, с чем мы категорически не согласны. Но вместо того, чтобы высказаться, мы перекладываем ответственность на государство, крупные организации и общество в целом, а сами остаемся в стороне. Почему люди, обладающие моральными принципами и доброй душой, зачастую ничего не делают? Тогда как, казалось бы, небольшое действие может привести к значительным позитивным переменам? Заманчивым является занятие - обвинять злых людей, а с себя (хороших людей) полностью снимать ответственность! Но ведь это бездействие т.н. «хороших людей» позволяет злу укреплять свои позиции.

Любое недостойное поведение в трудовом коллективе продолжается отчасти потому, что большое количество сотрудников боятся, что протест им дорого обойдется. Страх расплаты заставляет их молчать даже перед лицом крайне недостойного поведения. Так, мета-анализ «Ведомостей» и аналитической компании Online Market Intelligence (OMI) домогательств интимного характера показал, что только приблизительно одна четверть сотрудниц сообщают об этом начальнику, и только от 2 до $10 \%$ подают официальную жалобу [1, с.12]. Кроме того, «из-за неосуществления профессиональных устремлений женщины испытывают новые формы психологического насилия» - утверждает автор Ташлыкова Н.Ю. [6, с.260]. Домо-
Пухир Валентина Михайловна

К.ф.н., дочент, РГУ им. А.Н. Косыгина

(Технологии. Дизайн. Искусство.) va-lenta@bk.ru

Аннотация: В статье рассматриваются факторы, которые заставляют молчать 0 плохом поведении на работе, а также стратегии, которые могут использовать руководство коллектива и рядовые служащие для изменения культуры общения в профессиональном коллективе и укрепления гражданской позиции. На основании конкретных социальных наблюдений автор объясняет, почему люди на работе не всегда отстаивают собственные ценности и идеалы, и показывает, как это можно изменить. В статье представлены виды, формы и методы поощрения этичного поведения сотрудников. Особое внимание уделено нематериальным формам поощрения.

Ключевые слова: общение, этичное поведение, поощрение, молчание, лидер, культура высказывания.

гательства и насилие на работе являются, прежде всего, следствием безграничной власти начальника над подчиненными, полагает Елена Гапова, директор института гендерных исследований. По ее словам, наиболее бесправны работники мелких предприятий, где отсутствуют правила корпоративной этики, не оформлены должным образом трудовые соглашения и все вопросы решает хозяин, где сотрудники имеют низкую квалификацию и легко заменимы [1, с.9]. И чаще всего компании, чьи сотрудники жалуются на сексуальные домогательства со стороны коллег или руководителей, не предпринимают ничего. А некоторые наниматели считают, что жалобщик виноват сам и что это может привести к его увольнению. Правда, больше трети работодателей помогают пострадавшим - переводят их в другой отдел на аналогичную должность. И лишь единицы способны выплатить жертве денежную компенсацию или даже компенсировать моральный вред повышением в должности.

Закон мало чем может помочь пострадавшим: В Трудовом кодексе нет понятия «харассмент». Есть лишь статья 133 в Уголовном кодексе - о понуждении к действиям сексуального характера. Однако, если не было прямого насилия и все ограничивалось только приставаниями, ничего доказать невозможно. Поэтому жертвы чаще всего предпочитают молчать, перейти в другой отдел или просто уволиться с работы.

Молчание перед лицом плохого поведения особенно 
распространено, когда люди имеют прямую власть над нижестоящими. Последствия сопротивления могут быть не в пользу пострадавшего. В ходе проверки профессиональных бухгалтеров в одной из компаний было установлено, что 60\% из них были замечены в правонарушениях на своем рабочем месте: неправильная классификация отчетов о расходах, манипуляции с зарплатой, перечисление зарплаты со счета фирмы на подставных лиц, кража канцелярского имущества [3, с.14]. Большинство сослуживцев предпочитают об этом не говорить. Чаще всего причиной молчания была тревога по поводу потери работы или ухудшения рабочей обстановки.

Даже когда расплата за противостояние маловероятна, у работников иногда находятся личные мотивы, чтобы игнорировать плохое поведение. Когда имеет место факт корпоративного мошенничества, эти люди могут получать прямую выгоду от того, что якобы не замечают неэтичного поведения. Они даже могут получить финансовые поощрения за то, что делают вид, что ничего не знают. Это происходит потому, что профессиональные последствия за противостояние плохому поведению могут быть существенными, особенно если мошенник занимает высокую позицию. Интуитивные, привычные шаблоны поведения нередко берут верх над людьми. С точки зрения этики, это может выразиться в эгоцентричном подходе «Я важнее всего!», когда краткосрочная выгода становится приоритетной перед долгосрочными последствиями, которые могут спровоцировать этические ошибки.

В одной из компаний по разработке программного обеспечения проводили собрание по поводу целей бюджета на предстоящий год. После встречи начальник обратился к единственной женщине: «Эй, как насчет того, чтобы убрать за нами со стола? Разве у женщин не лучше это получается?». Конечно же, данное высказывание является дискриминационным и неуместным. Но поскольку комментирующее лицо было руководителем (а не коллегой или подчиненным), женщине было тяжелее решить, что делать, и она понимала, что возражение может ей дорого обойтись.

Бывают случаи, когда руководители увольняют сотрудников за неэтичное поведение. Исследования показали, что взаимосвязь между неэтичным поведением и изгнанием сотрудника зависит от того, насколько продуктивным, важным для компании является работник. Для тех, кто не очень продуктивен, неэтичное поведение (такое как, например, фальсификация отчетов о времени или расходах, или неправомерное использование конфиденциальной информации) приводит к игнорированию коллег на работе или даже к притеснению со стороны коллег. Но для тех, кого очень ценит руководитель как высокопроизводительного работника, может и не быть никакой связи между неэтичным поведением и изгнанием с работы. Другими словами, высокая производительность может компенсировать неэтичное поведение.

В любом профессиональном коллективе противостояние недостойному поведению влечет за собой издержки. Они особенно велики в тех организациях, где традиции основываются, главным образом, на преданности организации. Даже если это поведение напрямую противоречит их ценностям. Это относится, в первую очередь, к вооруженным силам и полиции. В полицейской культуре практически всех стран существует т.н. «кодекс молчания». Многие из них замечают проступки других офицеров, но никому не сообщают о них. Но ведь молчание людей автоматически делает их соучастниками. Причем, психологи выявили, что когда работник делает маленький шаг в неверном направлении, ему уже становится трудно изменить этот «скользкий» курс. Вот как один бывший американский финансовый директор описал этот процесс: «Преступность начинается с малого и прогрессирует очень медленно. Сначала вы работаете неофициально. Некоторые говорят, что это и не преступление. И как только вы встаете на скользкую дорожку, с нее трудно сойти. Все, что вам нужно сделать, это просто пересечь черту. И ты уже в деле. А когда ты уже в деле, ты навсегда там» $[8$, с.24 ].

Безусловно, проблемное поведение наносит ущерб профессиональным коллективам всех типов - от учебных заведений и корпораций до больниц, военных и полицейских органов. Чтобы устранить такое плохое поведение, нужно больше, чем просто обнаружить этих «плохих людей». Для этого, на наш взгляд, необходимо весомое изменение профессиональной культуры. Рабочие места должны способствовать воспитанию этической культуры, которая запрещала бы покрывать недостойное поведение коллег. Одним из ключевых факторов, который препятствует многим людям говорить и заставляет молчать, является страх социальных последствий. Людей, которые сообщают о неэтичном поведении своих коллег или начальства, часто называют «стукачами» или «крысами». Но даже к людям, которые выполняют роль «осведомителей» нередко относятся с подозрением и даже с презрением.

Бывший вице-президент подразделения исследования и разработок табачного гиганта «Brown and Williamson», доктор Джеффрри Уайганд дал в 2011 г. обличительное интервью телепередаче «60 минут» (CBS) и раскрыл населению всего мира информацию об истинном, смертельном вреде никотина. Он обнаружил, что вышеназванная табачная компания намеренно добавляла вредоносные химикаты в табак, чтобы сигареты вызывали больше привыкания. В своем интервью он сказал: «Тех, кто выдает имена нарушителей, нужно называть подругому. Почему? Их прозвища имеют уничижительный 
оттенок - крыса, сплетник, доносчик, стукач, перебежчик». Интервьюэр спросил, как он предлагает назвать этих людей. Доктор Уайганд ответил: «человек совести».

Что может сделать организация для создания культурных традиций, в которых действительно высоко ценится этичное поведение? Некоммерческой компания Ethical Systems в Нью-Йоркском университете предоставляет компаниям и организациям научно-ориентированные стратегии для создания профессиональной культуры, которая должна поощрять этичные решения. Глава этой компании, известный как «профессор этического лидерства» Джонатан Хайдm утверждает, что «лидеры должны быть готовы нанимать, увольнять и продвигать на основе этичных ценностей, а не просто достигать конечных целей или способствовать росту бизнеса» [7, с.31]. Первое, что должны делать лидеры для создания профессиональной культуры - на собственном примере формировать этичное поведение. Это может быть понижение своей и своих первых заместителей зарплаты, если организация находится в кризисном состоянии. Также это может быть отказ от выгодной сделки, если она может навредить инвесторам. Моральное лидерство можно показать, обустроив свой рабочий кабинет такого же размера, как и у всех рядовых сотрудников организации.

Очень важным и очевидным фактором, по мнению Хайдта, является то, что компаниям необходимо искать лидеров, которые будут моделировать этичное поведение. Они должны быть осторожными, вдумчивыми, умеющими обращать внимание на детали. Такие лидеры обычно не принимают поспешных решений и не допускают грубых ошибок. Они способны адекватно оценить свою нравственную идентичность: являются ли они внимательными, честными, заботливыми, справедливыми. Нельзя не согласиться с Джонатом Хайдтом! Действительно, этичное руководство компании приводит к достаточно большой прибыли, а метод «быстрого и короткого пути» - нет. Руководители с высокими этическими характеристиками выступают для своих подчиненных как «борцы за правое дело», для которых общее благо сотрудников, партнеров и клиентов находится в приоритете. Те же руководители, которые обладают низкими этическими характеристиками, демонстрируют обратное: они не выполняют обещаний, лгут, обвиняют других в неудачах компании, несправедливо наказывают сотрудников за ошибки, не проявляют заботы и сочувствия.

Таким образом, этичные лидеры мотивируют своих сотрудников на лучшее поведение. А это, как уже было отмечено ранее, окупается сполна. Почему? Потому что люди, работающие под руководством этичного лидера, достигают более высокой степени удовлетворенности своей работой и, следовательно, выполнением своей миссии. Большинство западных предпринимателей хорошо понимают, что главным достоянием любой компании или фирмы является человек, поэтому стараются приблизить служащего к этичному лидеру, помогают ему занять более высокую ступеньку в карьерной лестнице. Наиболее эффективными становятся отношения, когда хозяин и работник выступают как партнеры и единомышленники.

К сожалению, различные наблюдения указывают на то, что люди, занимающие высокие посты, с меньшей вероятностью выбирают этический путь, чем люди, занимающие более низкие посты. Руководители различных сфер нередко проявляют лицемерие, которое свидетельствует о том, что люди, обладающие властью, придерживаются более высоких рабочих стандартов по отношению к сотрудникам, чем к самим себе, даже если они временно обладают такой властью. Эксперт по социальной психологии Адам Галинский отмечает, что некоторые политики используют государственные средства для частной выгоды, при этом призывали к уменьшению размера правительства. Или пасторы, которые активно призывают оказывать помощь бедным, но при этом владеют огромными особняками и частными самолетами [2, с. 17].

Что же могут сделать компании, чтобы убедиться в том, что они нанимают этичных лидеров, у которых слова не расходятся с делами? Профессор Хайдт рекомендует выбирать таких кандидатов, которые будут стремиться получать не краткосрочные выгоды, когда их неэтичные действия могут быстро окупиться, а таких кандидатов, которые способны видеть долгосрочные перспективы существования и развития компании. И эти лидеры должны установить одинаковые этические правила как для себя, так и для подчиненных. Они обязаны на личном примере показывать приверженность принципам этики. Более того, они должны обладать особыми методами поощрения этичного поведения их работников.

Поощрение - это способ мотивации, основанный на вознаграждении сотрудников за добросовестный труд, а, следовательно, вклад в развитие предприятия. Поощрение необходимо, когда нужно стабилизировать должное отношение сотрудников к трудовому процессу. Такие сотрудники, как правило, соблюдают этичную культуру. Они способны четко и недвусмысленно демонстрировать свою нетерпимость к неэтичному поведению на всех уровнях. Опыт показывает, что лучший эффект будет достигнут в результате минимального отрезка времени между действиями сотрудников и их вознаграждением (например, через неделю). Опыт показывает: если человек знает о предстоящем в скором времени поощрении, эффективность его работы в организации увеличивается в несколько раз. Главным результатом поощрения будет достижение желаемого эмоционального состояния работников. Хорошо, если руководитель зна- 
ком с личными характеристиками и особенностями каждого работника, которого он хотел бы поощрить. Зная личные потребности своих сотрудников, руководитель может выбрать удобную ситуацию для вознаграждения, либо действовать согласно специально разработанному сценарию. В любом случае, поощрение должно сопровождаться искренними чувствами, иначе оно не будет мотивировать работников на позитивный настрой к работе и соблюдению норм этичной культуры. Любое поощрение в рабочем коллективе должно получить положительную огласку. Это поднимает авторитет, престиж и уважение сотрудников. Очень важно учитывать фрактор справедливости поощрений внутри коллектива. В противном случае, неграмотно организованное и проведенное поощрение работников в коллективе может привести к негативно отразиться на корпоративном климате. И наоборот: правильно обоснованные и справедливые поощрения сплачивают и объединяют коллектив в одну команду. Вознаграждение - это то, что человек считает для себя наиболее ценным при выполнении своей работы. Однако, само понятие ценности для всех работников разное. Кого-то можно наградить подарком, путевкой в санаторий или в туристическую поездку, премировать или помочь с ссудой - варианты зависят от возможностей организации. Но бывает, что для материально обеспеченного человека большей ценностью является отдых в компании друзей и единомышленников, нежели дополнительная сумма денег.

Очень важным стимулом для поддержания культуры этичного поведения работников являются слова поощрения. Они должны быть конкретными, указывать на то или иное положительное действие, задание, безупречно выполненную работу. Слова поощрения должны быть сказаны своевременно - непосредственно вслед за успешно завершенной работой. Заслуживают поощрения любые успехи подчиненных, независимо от степени их значимости. Но при этом работниками непременно должны соблюдаться правила этичного поведения в коллективе. Большое значение имеет грамотная формулировка слов поощрения. Ведь публичное поощрение в присутствии коллег для человека особенно важно, нередко является даже более ценным, чем материальное поощрение. Эффективность похвалы состоит в том, что она стимулирует работника и умножает его трудовые усилия [5, с.90-91] К похвале привыкают, с каждым разом ее хочется все больше. Иной раз отсутствие похвалы уже воспринимается как наказание. Намного лучше хвалить за меньшие достижения, но чаще, поскольку это формирует длительную мотивацию. Поддерживать и поощрять подчиненных, верить в них, хвалить искренне и с любовью - это благородное и благодарное дело! Оно окупится сторицей! Признавая заслуги своих подчиненных или коллег, человек делает шаг, чтобы привлечь сотрудника на свою сторону. Постепенно можно поднять планку этичных поступков, за которыми последует похвала.
Можно привести несколько примеров слов поощрения: «Вы безупречно выполнили эту работу!», «Отличный результат! Первое место - за вами!», «Вам удалось в столь сжатые сроки выполнить такую сложную работу!», «Ход ваших мыслей мне нравится», «Поздравляю вас с успехом! Теперь вы видите ваши возможности», «Сегодня вы превзошли себя!», «Я надеюсь, что и дальше дела пойдут много лучше», «Ваш опыт будет очень полезен для всего нашего коллектива» и т.п.

Нематериальной формой поощрения персонала также является публичная благодарность - официальное моральное поощрение сотрудника, с занесением в приказ, о котором руководитель объявляет всему коллективу. Если работник этого заслуживает, почему бы не похвалить его на общем собрании или каком-нибудь корпоративном мероприятии, где присутствует большинство его коллег? Можно даже разместить небольшую статью в газете, или дать интервью для радио или TВ. А затем можно подарить этому сотруднику оформленную в приличной рамке вырезку из статьи или диск с эфиром передачи, в котором говорилось о нем все положительное.

Одобрение, как и похвала, является неформальным моральным поощрением сотрудника в течение рабочего процесса, когда руководитель замечает трудовые старания и этичное поведение работника, которые приближают его к необходимому результату. Очередной вид неформального нематериального поощрения работника в процессе выполнения поставленной задачи, а также неукоснительного соблюдения этических нормы - это поддержка в случае возникших сомнений, трудностей в выборе методов и способов деятельности. В качестве официального нематериального поощрения может выступать снятие ранее наложенного на сотрудника взыскания (например, путем составления соответствующего приказа и его оглашения).

Как уже было отмечено выше, на руководителей организацией возложена дополнительная ответственность за поддержание культуры этичного поведения. В частности, руководитель обязан на личном примере показывать приверженность принципам этики, создавать и поддерживать такую рабочую атмосферу в коллективе, в которой каждый сотрудник чувствовал бы себя комфортно. И непременно четко и недвусмысленно демонстрировать свою нетерпимость к неэтичному поведению. Причем, посыл должен исходить не только от руководителей организаций, но и от коллег. Обучение правилам этичной культуры должно быть многогранным и полным, а не ограничиваться только просмотром видео, которое сотрудники обычно смотрят без всякого энтузиазма перед работой. Руководителям компаний необходимо научиться доносить свои ожидания о моральном поведении работником как в больших, так ив 
малых масштабах. Пресечение неэтичного поведения на изначальной стадии имеет важное значение, поскольку мошенническая практика со временем приобретает все больший масштаб. Если, например, какой-то нечестный автор присваивает себе чужую статью (или даже ряд статей) и он видит, что это ему вроде бы «сходит с рук», следовательно, ему надо каким-то образом объяснить коллегам, что он - «хороший человек». И если это коллеги могут посчитать «нормальным», значит он должен придерживаться этого «нормального» действия. В таком случае продолжать махинации этому человеку становится намного проще. Поэтому и руководителю, и всей компании необходимо устанавливать правила, которые ограничивают и, в конечном итоге, жестко пресекают привлекательные, но мошеннические действия. Организациям также необходимо настаивать на том, чтобы сотрудники на всех позициях соблюдали одни и те же этические нормы. Нередко руководители компаний игнорируют неэтичное поведение «звезд», которых, по их твердому убеждению, они не могут потерять. Это академики, которые приносят гранты, менеджеры хеджфондов с богатыми клиентами, кинопродюсеры и т.п. Сотрудники, которые наблюдают, как этим «звездам» сходит с рук их сомнительное поведение, понимают, что руководство организации терпимо относится к плохому поведению. Это осознание значительно понижает их готовность сообщать о нарушениях этических правил и может даже их провоцировать на неэтичные действия. Поэтому одной из важных стратегий борьбы с корпоративным мошенничеством является, на наш взгляд, разработка эффективной политики противодействия неэтичному поведению. Согласно социологическому опросу ряда компаний, люди значительно чаще сообщают о мошенническом поведении руководству в своей компании, когда не боятся расплаты за это. Все тот же профессор Уайлд уверен в том, что информация о нарушениях заставила акционерные компании проявлять большую осторожность, чтобы уменьшить риск появления экономических и правовых проблем в будущем.

Таким образом, мы можем сделать вывод: нежелание терпеть неэтичное поведение окупается. У сотрудников, которые приветствуют этичное поведение, не будет соблазнов предпринимать даже небольшие шаги в направлении плохого поведения. У них не будет страха и опасений, когда они будут информировать о проблемном поведении сотрудников, что поможет остановить его на ранних этапах.

В Трудовом кодексе РФ нет норм, обязывающих сотрудника быть со всеми вежливыми и корректными в рамках рабочего процесса, сообщать о нарушениях норм и правил профессиональной этики, а работодателю - делать все возможное по созданию благоприятного психологического климата в коллективе. Поэтому создание культуры приоритетного этичного поведения для всех сотрудников может быть связано с определенными изменениями в нормах конкретной организации. Но ведь в конечном итоге это поможет прибыли и вообще - созданию комфортных условий для работы.

Одним из самых простых способов приобщения людей к этическому поведению - это создание скрытых напоминаний. В европейских странах и в США многие колледжи и университеты требуют, чтобы студенты подписывали т.н. «клятву чести» в начале экзамена, в которой говорится, что они не должны списывать сами и не давать свои работы для списывания другим. Эта стратегическая установка направлена на то, чтобы напомнить студентам о важности честной работы и повысить их самооценку перед сдачей экзамена. А повышение уровня самосознания, как утверждают психологи, понижает склонность людей отказываться от выполнения групповых заданий. Это происходит потому, что почти все считают себя хорошими людьми, которые совершают нравственно правильные поступки. И даже совсем небольшие подсказки, такие как, например, подпись своего имени в верхней части страницы, вполне могут подтолкнуть людей к более этичному поведению. Когда люди подписывают свои имена, это им напоминает, кто они есть. Им также это напоминает об их намерении быть хорошими людьми, которые поступают правильно. Этот вид тонкого намека имеет большое значение, поскольку неэтичное поведение часто возникает не после тщательного и обдуманного мышления, а случайно и непреднамеренно. Ведь студент очень волнуется во время экзамена и спонтанно решает посмотреть на ответы соседа, чтобы просто, как он думает, «проверить ответ». Или журналист, стараясь уложиться в сроки, может выдать чужую цитату за свою. Это делается очень быстро и непреднамеренно. И мало кто из них думает (если вообще думает) о возможных последствиях.

Есть еще один ненавязчивый способ подтолкнуть людей к этичному поведению на работе - это попросить их задуматься о том времени, когда они вели себя плохо и о котором теперь сожалеют. Исследования показали, что просьба поразмыслить над собственным недостойным поведением в прошлом, действительно уменьшила готовность сделать это снова.

Еще одной подсказкой, которая напомнит людям о необходимости быть честным в профессиональном коллективе, может быть размышления в письменном виде о соблазнах неэтичного поведения. Это уменьшит намерение работников притворяться больными, воровать казенное имущество, копировать несколько предложений из Википедии, подделывать чужую подпись или медленно работать, чтобы избежать дополнительных заданий. Напоминание о том, какими соблазнительными могут быть нечестные действия сотрудников, в какой-то 
степени, усиливают способность сопротивляться им. Это срабатывает потому, что если людей просят остановиться и подумать о своем поступке, они обычно признают, что действовали неправильно.

Следует отметить, что этичное поведение не требует длительного и интенсивного обучения персонала отделом кадров или деканами вузов и колледжей. Ненавязчивые, едва уловимые стратегические методы могут хорошо помочь в этом деле.

В атмосфере этичной культуры сотрудники могут спокойно обсуждать проблемное поведение в коллективе. Как уже отмечалось выше, молчание способствует недостойному поведению и может привести к реальным затратам. Поэтому, на наш взгляд, есть смысл в том, чтобы составлять программы, направленные на формирование культуры отчетности, в рамках которой все сотрудники несут персональную ответственность за поддержание здоровых условий работы. В программе должны быть конкретные инструкции: как высказывать свое мнение или вмешиваться в неоднозначную ситуацию, а также как подать жалобу, когда они стали свидетелями недостойного поведения. Некоторые работники опасаются, что создание культуры высказывания может привести к созданию неудобной обстановки работы в коллективе, когда они должны будут отчитываться друг перед другом. Но это не так. Формирование культуры этичного поведения руководством означает, что абсолютное большинство сотрудников будут следовать соответствующим этическим правилам и нормам. А те некоторые сотрудники, которые не желают соблюдать правила, вынуждены будут прекратить недостойное поведение на ранней стадии.

Опыт исследований неэтичного поведения в различных компаниях показал следующее: сотрудники с большей готовностью сообщают о недостойном поведении, если уверены, что и руководители, и все коллеги, разделяют их обеспокоенность. Но многие люди не утруждают себя сообщениями о неэтичном поведении, если лично сталкиваются с его отрицательными последствиями со стороны начальства или коллег. Этот страх мести заставляет большинство сотрудников молчать даже в случаях крайне неэтичного поведения. Трудно поступать честно человеку, если он знает, что заплатит за это высокую личную или профессиональную цену. Это требует большого нравственного мужества.

ЛИТЕРАТУРА

1. «Ведомости» (Карьера) // vedomosti.ru>archive/2020/01/23

2. Галинский Адам: как отстаивать свое мнение. //ideanomics.ru/lectures/12777

3. Желенкова Елена. Как обманывают бухгалтеры? Мошеннические схемы бухгалтеров. //1c-wiseadvice.ru

4. Корнеенков С.С. Психология и этика профессиональной деятельности. М.: Юрайт, 2019. 304 с.

5. Пухир В.М. Этикет деловых комплиментов // Психология диалога и мир человека. Сборник научных трудов. - Уфа: Изд-во БГПУ, 2015. 224 с

6. Ташлыкова Н.Ю. 0 диалектике лидерства, насилия и свободы воли: философский и социологический аспекты. /Материалы Десятой международной научной конференции РАИЖИ и ИЭА РАН. 2017. Издательство: Институт этнологии и антропологии им. Н.Н. Миклухо-Маклая РАН (Москва). С. $260-262$.

7. Хайдт Джонатан. Как компании вынуждают сотрудников нарушать закон. //vedomosti.ru/management/articles/2017/04/26/

8. Catherine A. Sanderson. The Bystander Effect. The Psychology of Courage and How to be Brave. https://www.livelib.ru/author/1684666-ketrin-sanderson

9. Sub I. «Boiling the frog slowly: The immersion of C-suite financial txtcutives into fraud» / Journal of Busines Echics (July 2018), p.1 